\title{
Measuring diaphragm movement and respiratory frequency using a novel ultrasound device in healthy volunteers
}

\author{
Håvard Andreassen Sæverud ${ }^{1}\left[\right.$ C Ragnhild Sørum Falk ${ }^{2} \cdot$ Adam Dowrick $^{3} \cdot$ Morten Eriksen $^{3} \cdot$ Sigurd Aarrestad $^{1,5}$. \\ Ole Henning Skjønsberg ${ }^{1,4}$
}

Received: 28 August 2019 / Accepted: 25 October 2019 / Published online: 6 November 2019

(c) Società Italiana di Ultrasonologia in Medicina e Biologia (SIUMB) 2019

\begin{abstract}
Purpose To evaluate the ability of a novel ultrasound (US) device, DiaMon, to monitor diaphragm movement via its proxy liver movement, and compare it with the respired flow measured with a flowmeter, in awake and healthy volunteers. We wanted to (1) establish the optimal anatomical position for attaching the DiaMon device to the abdominal wall, and (2) evaluate the accuracy of continuous monitoring of respiratory frequency.

Methods Thirty healthy subjects were recruited. The DiaMon probe was applied subcostally in four different positions with the subjects in five different postures. The subjects breathed tidal volumes into a spirometer for 30-60 s with the DiaMon recording simultaneously.

Results The device detected a readable signal in $83-100 \%$ of the position/posture-combinations. The technical correlation between the two signals was highest in the anterior axillary-supine position (mean \pm SD: $0.95 \pm 0.03$ ), followed by paramidline-supine $(0.90 \pm 0.09)$ and midclavicular-supine $(0.89 \pm 0.12)$. The frequency measurements yielded a mean difference of $0.03(95 \%$ limits of agreement $-0.11,0.16)$ breaths per minute in the anterior axillary-supine position.

Conclusion The DiaMon device is able to detect liver movement in most subjects, and it measures breathing frequency accurately.
\end{abstract}

Keywords Ultrasound $\cdot$ Diaphragm $\cdot$ Respiration $\cdot$ Non-invasive

Electronic supplementary material The online version of this article (https://doi.org/10.1007/s40477-019-00412-2) contains supplementary material, which is available to authorized users.

Håvard Andreassen Sæverud

uxhvsv@ous-hf.no

1 Department of Pulmonary Medicine, Oslo University Hospital, Kirkeveien 166, 0450 Oslo, Norway

2 Oslo Centre for Biostatistics and Epidemiology, Research Support Services, Oslo University Hospital, Oslo, Norway

3 Respinor, Gaustadalleen 21, 0349 Oslo, Norway

4 Faculty of Medicine, University of Oslo, Oslo, Norway

5 Norwegian National Advisory Unit on Long Term Mechanical Ventilation, Haukeland University Hospital, Bergen, Norway

\section{Introduction}

Invasive mechanical ventilation (IMV) is in many circumstances a lifesaving treatment, however complications are common and their prevalence increases with the length of intubation [1-3]. In addition respirator treatment in an intensive care unit is expensive and is estimated to account for up to $13.3 \%$ of hospital costs, $4.2 \%$ of national health expenditures and more than $0.5 \%$ of gross domestic product in the USA [4]. Shortening the time on mechanical ventilation and reducing the number of reintubations could thus have a positive impact for the individual patient whilst simultaneously reducing costs.

In healthy people the dome-shaped diaphragm is the major muscle of respiration [5]. In patients with respiratory compromise, monitoring its function may be important in order to evaluate the patient's ability to uphold adequate ventilation. Loss of function starts early when the diaphragm is incapacitated, such as when intubated and on invasive mechanical ventilation (MV) [6,7], and it has been shown 
that a large proportion of people on $\mathrm{MV}$ in the intensive care unit (ICU) cannot be easily liberated from the ventilator. It seems likely that impaired diaphragm function contributes to these problems, and this has a negative impact on prognosis [8-12].

Several techniques have been developed trying to evaluate respiratory efforts, but their use have been hampered by the fact that they are either invasive (electromyography), uncomfortable for the patient (transdiaphragmatic pressure measurements), not readily available (magnetic resonance imaging) or involve radiation (fluoroscopy) [13-15]. An abundance of non-invasive methods have been tried, examples being the respiratory inductive plethysmography of Konno and Mead [16], direct measurement with flowmeters using ultrasound [17], accelerometers for remote surveillance [18] and photoplethysmography [19], which, even though the method is not completely understood, takes advantage of the change in microcirculation with respiration. It has been found that movement of the abdominal structures like the liver closely mirrors movement of the thoracic diaphragm [20, 21], and there has been increasing interest in using US for evaluating the function of the diaphragm [15, 22-26], and it has been suggested that US of diaphragmatic excursion might be used for detecting obstruction in patients suspected of having COPD [27, 28]. However, this technique requires specialist knowledge and training, and in its traditional form is suitable for real time evaluation only, and not for surveillance over a prolonged period of time.

Furthermore, closer monitoring of respiratory frequency (RF) in patients outside of the ICU or highdependency units may be warranted as an abnormal RF has been shown to predict serious clinical events [29-33]. However, of the four vital signs, RF is the least frequently recorded [32, 34], potentially leading to delay in response to patient deterioration. When measuring RF, the current standard practice is manual counting of RF by a member of the clinical team, though this method is known to suffer from inconsistencies [35]. Spirometry can be used at single points in time, but cannot provide continuous measurements of RF. Capnography provides this opportunity, but is not readily available in general wards. Given all this, an objective RF monitor that may improve patient care and decrease healthcare costs is warranted [30].

The DiaMon device (Respinor AS, Oslo, Norway) is a novel medical device which uses Doppler US (US) to measure the movement of the liver as a proxy of diaphragm movement and can provide continuous measurement of diaphragm excursion and RF. The system is easy to use, requires little training, does not involve radiation and is not uncomfortable for the patient.

The aim of this first study of the novel US device (DiaMon) was to compare diaphragm movement and RF, measured with DiaMon, with respiratory flow and rate from a spirometer as the gold standard in order to (1) establish the optimal anatomical position for attaching the DiaMon device to the abdominal wall, and (2) evaluate the accuracy of continuous monitoring of RF.

\section{Methods}

The study protocol was approved by the Regional Committee for Medical and Health Research Ethics (REK 2016/637) and is in accordance with the 1964 Helsinki Declaration and its later amendments. All participants provided informed consent prior to commencing any study procedures.

\section{Participants}

Healthy volunteers were recruited among employees, staff and students at Oslo university hospital from September 2016 to April 2017. All persons who were not pregnant and were able to lie down for the required period of time were eligible for inclusion. People with abdominal or thoracic surgery within the last 6 months were excluded.

All candidates were asked about comorbidities and concomitant medication (prescribed or over-the counter). Height and weight were measured by the principal investigator or a trained nurse. Body mass index (BMI) was calculated $(\mathrm{kg} /$ $\left.\mathrm{m}^{2}\right)$.

\section{Equipment}

The DiaMon P2.1 device records the respiratory motion of the liver using an all digital pulsed Doppler technique. US pulses at $2.0 \mathrm{MHz}$ are emitted at an angle of $45^{\circ}$ from the transducer attached to the right, subcostal surface into the underlying tissue, and the phase relationship between successive received echoes is used to estimate tissue velocity and displacement. These values are pairwise electronically compared to determine the displacement of the tissue that has occurred, and the total displacement is calculated by summation and displayed and stored at a rate of $200 \mathrm{~Hz}$. The US probe is centrally cast into a circular polyvinylchloride (PVC) cache that is filled with silicone (Elastosil RT 601, Wacker Chemie AG, Munich), giving the probe a total diameter of $57 \mathrm{~mm}$ (Fig. 1). A patented 0.4-mm-thick sonolucent double-sided adhesive silicon tape for single use is used to attach the probe to the patient. The sensor is cabled to a control unit which consists of a monitor and personal computer that acts as the user interface and hardware for saving the anonymized data for later processing. 


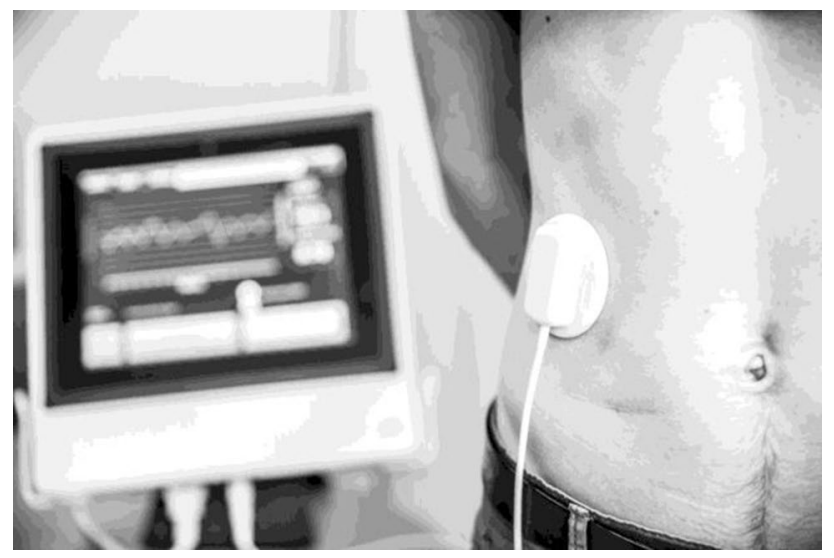

Fig. 1 The probe attached to the body

\section{Measurements}

After synchronizing the clocks of the spirometer and the DiaMon, the DiaMon was applied in the midline approximately $2 \mathrm{~cm}$ below the xiphisternal joint with the subject lying supine. The subject was asked to breathe into an ultrasonic transit-time spirometer sensor (Spirare, Easy on-PC, NDD Medizintechnik, Zurich) that was able to store repeated respiratory cycles at a rate of $200 \mathrm{~Hz}$. The subject breathed tidal volumes for 30-60 s, and the respiratory cycles were recorded simultaneously with the DiaMon and the spirometer. The procedure was then repeated with the subject lying on the right side, the left side, sitting at approximately $60^{\circ}$ and standing.

We then repeated the five patient postures in sequence with the probe in the paramidline position, anterior axillary position and finally the midclavicular position. In all positions the probe was placed approximately $2 \mathrm{~cm}$ below the lowermost costa. Having the probe in four different anatomic positions and the subject in five different postures yielded 20 different position/posture-combinations for each participant.

The upright, standing, position was part of the protocol for all probe positions in order to make sure there were no major differences in the measurements in these postures compared to the other postures. However, as these postures are irrelevant from a clinical point of view, we have excluded them from inferential analysis.

\section{Data handling}

The recorded data were transferred to a computer for analysis using custom-written software (TMT Pascal 4, TMT Development co., Framework Computers). In order to synchronize the recordings from the spirometer and DiaMon, an automated cross-correlation technique was used to align the time axis of the spirometer recording with the corresponding DiaMon recording. A readable signal was defined as a signal showing a pattern of sinusoidal waveforms by visual inspection, and a temporal alignment within $\pm 2 \mathrm{~s}$ from the expected value based on reading the computer clocks. An example of the waveforms derived from the DiaMon and the spirometer is shown in Fig. 2.

As the aim of the study was to evaluate the technical capability of the device and not to evaluate the variability in breathing patterns, a sequence of 20-30 s with sinusoidal waveforms was selected and used for breath-by-breath comparison. This was done when, based on a visual assessment, the spirometer signals reflecting tidal breathing were regular and consistent. Both the DiaMon and the spirometer sampled data with a frequency of $200 \mathrm{~Hz}$, thus yielding 4000-6000 raw data measurements for each combination of device, position and posture for each participant. Each raw data measurement is a reflection
Fig. 2 An example of synchronized recordings. Black: DiaMon recording - the position of the measured point in the liver measured as the distance from the starting point. Red: spirometer recording — volume of litre inhaled/exhaled

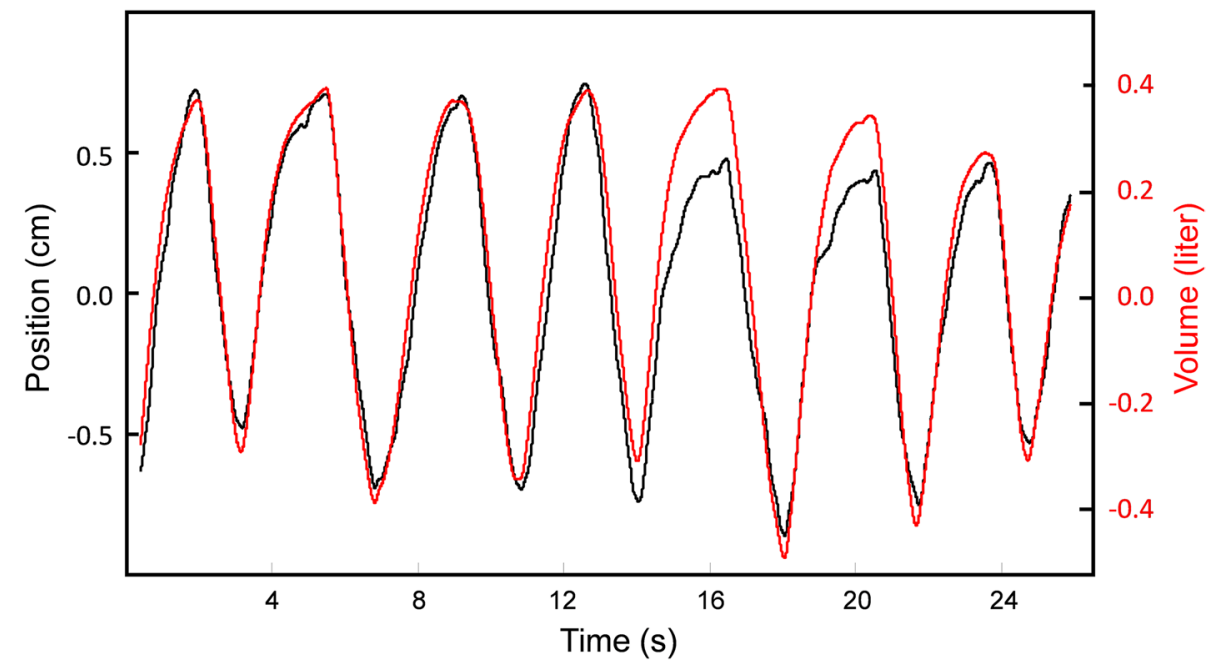


of either the position in time and space of the liver (DiaMon) or the direction and strength of the air flow in the spirometer.

To evaluate the signal quality, we calculated the correlation between the liver velocity signal $(V)$ from the DiaMon and flow $(F)$ from the spirometer. Velocity and flow signals were chosen to eliminate the inherent drift associated with position and volume calculated by integration.

The correlation coefficient $(r)$ between them was calculated as:

$$
r=\frac{\sum_{n=0}^{N}\left(V_{n}-\bar{V}\right)\left(F_{n}-\bar{F}\right)}{\sqrt{\sum_{n=0}^{N}\left(V_{n}-\bar{V}\right)^{2} \sum_{n=0}^{N}\left(F_{n}-\bar{F}\right)^{2}}} .
$$

$V_{n}$ and $F_{n}$ are individual samples numbered by $\mathrm{n}$ from 0 to $N, \bar{V}$ and $\bar{F}$ are the mean (average) values of $V$ and $F$, respectively. The correlation coefficient is a dimensionless number between -1 and 1 .

Table 1 Baseline characteristics of the participants

\begin{tabular}{lccl}
\hline & Mean & SD & Range \\
\hline Age (years) & 37.0 & 11.9 & $21.0-69.0$ \\
Height $(\mathrm{m})$ & 1.73 & 0.10 & $1.59-1.93$ \\
Weight $(\mathrm{kg})$ & 70.8 & 12.0 & $50.0-96.0$ \\
BMI $\left(\mathrm{kg} / \mathrm{m}^{2}\right)$ & 23.5 & 3.1 & $18.6-29.7$ \\
\hline
\end{tabular}

$N=30$

Fig. 3 Number of subjects in whom successful measurements were obtained for the various probe position and patient posture combinations Para paramidline position, antax anterior axillary position, midcl midclavicular position

\section{Statistics}

Descriptive statistics were given as number, mean, standard deviation (SD) and range. Graphically, the results are presented as barcharts or boxplots, as appropriate.

Measured respiratory frequencies were compared by performing an independent sample $T$ test on the difference between the two measurements, and the measurements were plotted as a Bland-Altman plot.

\section{Results}

\section{Participants}

Thirty healthy volunteers were recruited, 17 were women, 13 men. The characteristics of the participants are presented in Table 1. In one of the subjects, blood tests had previously shown a slight elevation in the liver function tests, but this had no functional impact. Two of the participants had been prescribed antihistamines for seasonal allergy, none of them were taking them at the time of the procedure. Six of the women used oral or implanted contraceptives, and six participants were taking over-thecounter vitamins or iron supplementations.

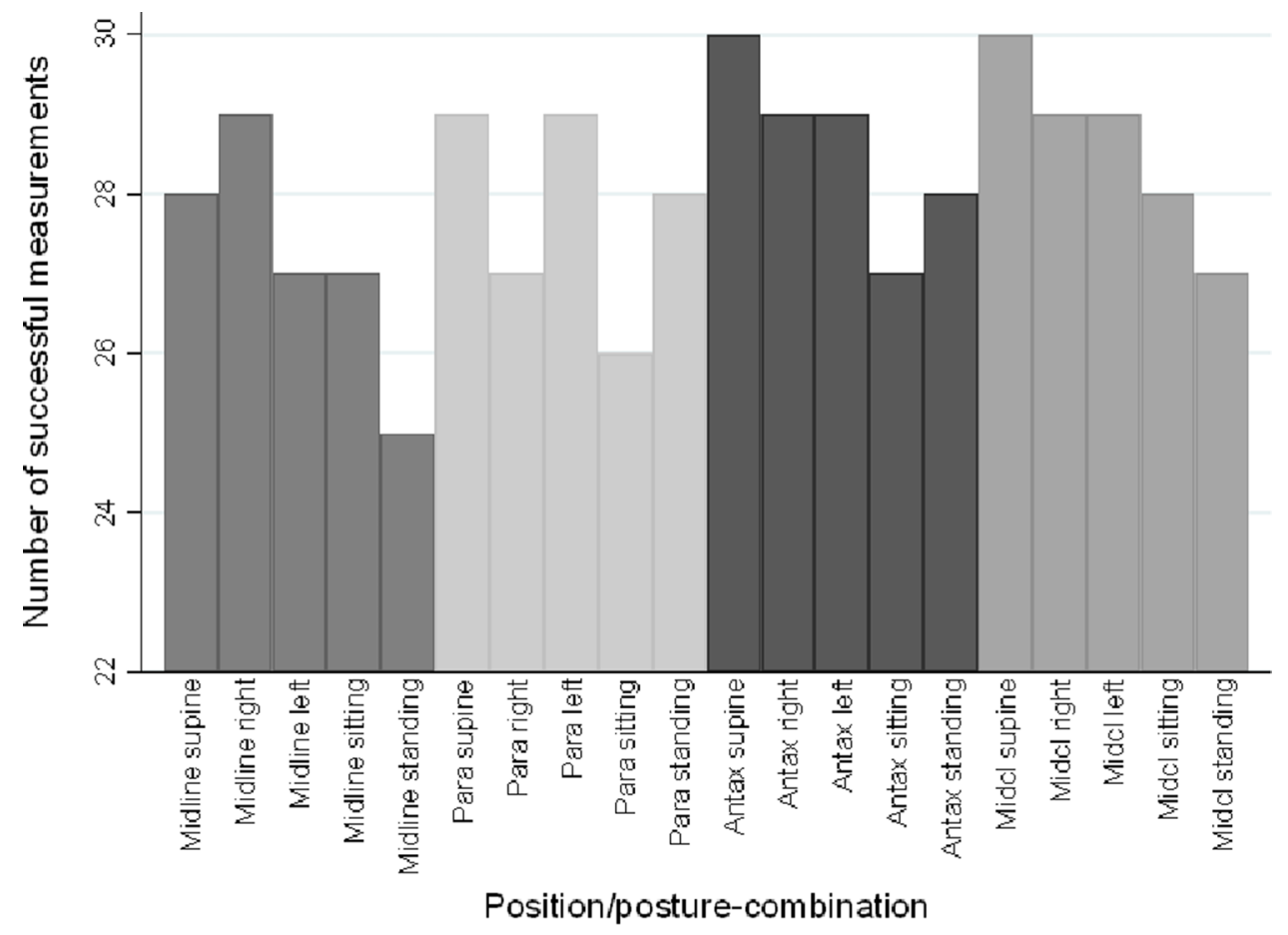




\section{Position}

The number of measurements with a readable DiaMon signal could be seen as a marker of usability. Placing the DiaMon probe in the anterior axillary or midclavicular line with the subject in the supine position proved able to record a readable signal in all subjects, while satisfactory recordings were obtained in all but one patient in the midlineright, paramidline-supine and left, anterior axillary-right and left, and midclavicular-right and left positions (Fig. 3).

\section{Signal quality}

The distribution of the correlation values between DiaMon and spirometer for the 30 participants is presented as boxplots in Fig. 4. The measurements with the highest correlations were found in the anterior axillary-supine position (mean 0.95 SD 0.03), followed by paramidline-supine (mean 0.90 SD 0.09), anterior axillary-standing (mean 0.90 SD 0.08 ) and midclavicular-supine (mean 0.89 SD 0.12).

\section{Respiratory frequency}

RF could be reliably measured with the US device. The Bland-Altman plot for the anterior axillary-supine US measurement and spirometry recordings is shown in Fig. 5, with a mean difference of 0.03 (95\% limits of agreement -0.11 , $0.16)$ breaths per minute. For paramidline-supine and midclavicular-supine, the values were $-0.11(-1.04,0.83)$ and
$0.13(-0.83,1.08)$ breaths per minute, respectively. The difference between the two ways of measuring RF is negligible.

\section{Discussion}

This study has evaluated the ability of a novel US device to record and measure the movement of the liver as a surrogate marker of diaphragm movement due to respiration efforts. We conclude that the best position for measurements is the anterior axillary position with the subject lying supine, and that the probe measures breathing frequency with excellent accuracy.

The probe has a high success rate when it comes to detecting a readable signal. As shown in Fig. 3, in the least favourable position, excluding the standing posture, we found acceptable signals in $87 \%$ of the subjects. In the most relevant positions it detected readable signals in at least $97 \%$ of the subjects. Overall, this means that the device should be able to provide useful information in most patients.

The best position for placing the DiaMon probe proved to be the anterior axillary line, approximately $2 \mathrm{~cm}$ below the lowermost costa with the subject lying supine. This yielded a very high correlation between the signals from the spirometer and the US device and resulted in a perfect estimation of respiratory frequency using the spirometer as the gold standard. Considering intensive care patients, this would be a position suitable for most patients. As a backup for patients
Fig. 4 Boxplot showing the distribution of correlation values from signal analysis by position and posture, $n=30$. The bottom and top of the box are the first and third quartiles, respectively, and the band inside the box is the median. The interquartile range (IQR; shaded box) is the middle $50 \%$ of the observations. The ends of the whiskers represent the lowest observation still within 1.5 IQR of the lower quartile, and the highest observation still within 1.5 IQR of the upper quartile. Any data not included between the whiskers are plotted as outliers (black dot) > 1.5 IQR]

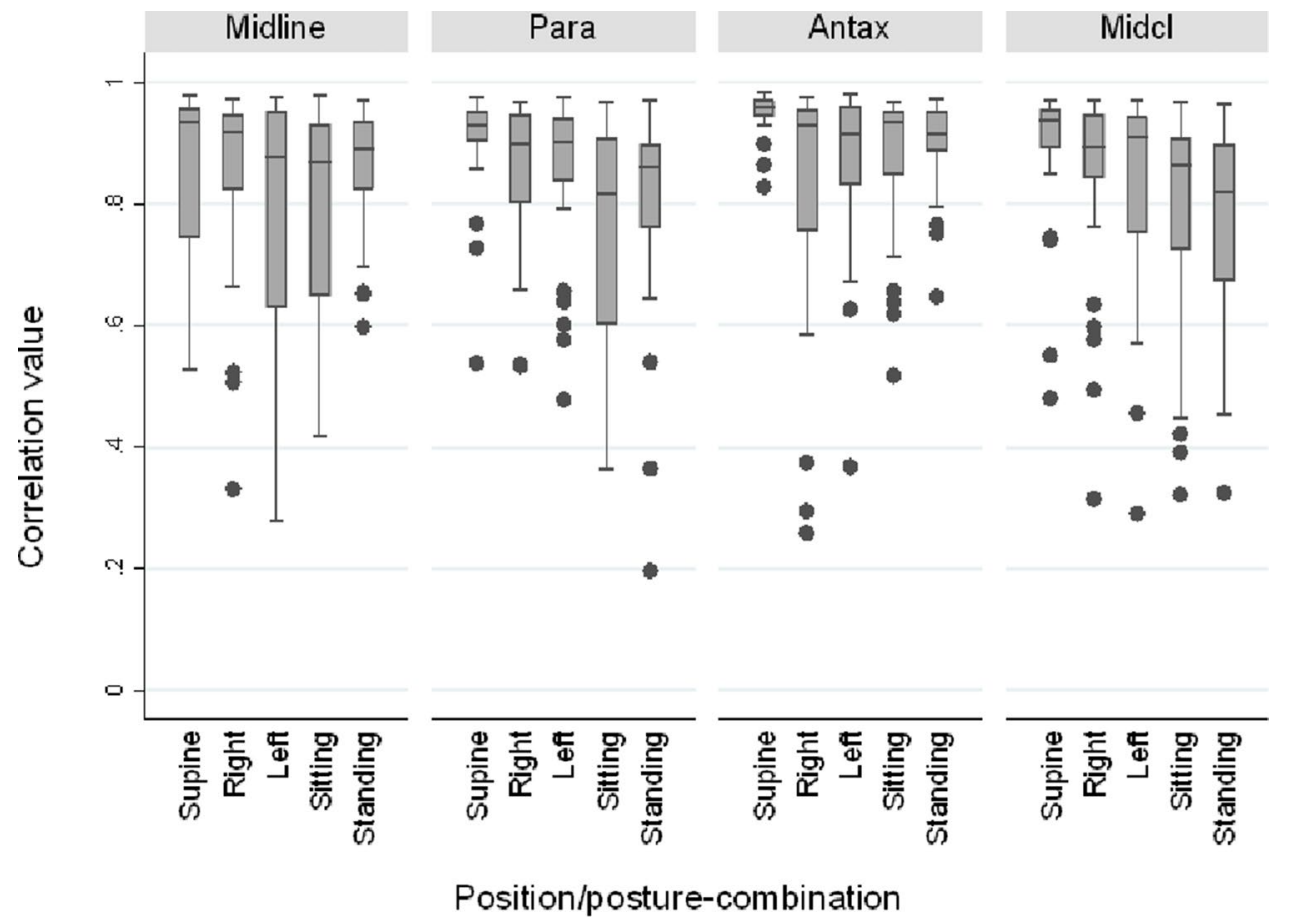


Fig. 5 Bland-Altman plot of the difference in measured respiratory frequency between the DiaMon and the spirometer in the anterior axillary-supine position. $Y=0$ is the line of perfect average agreement

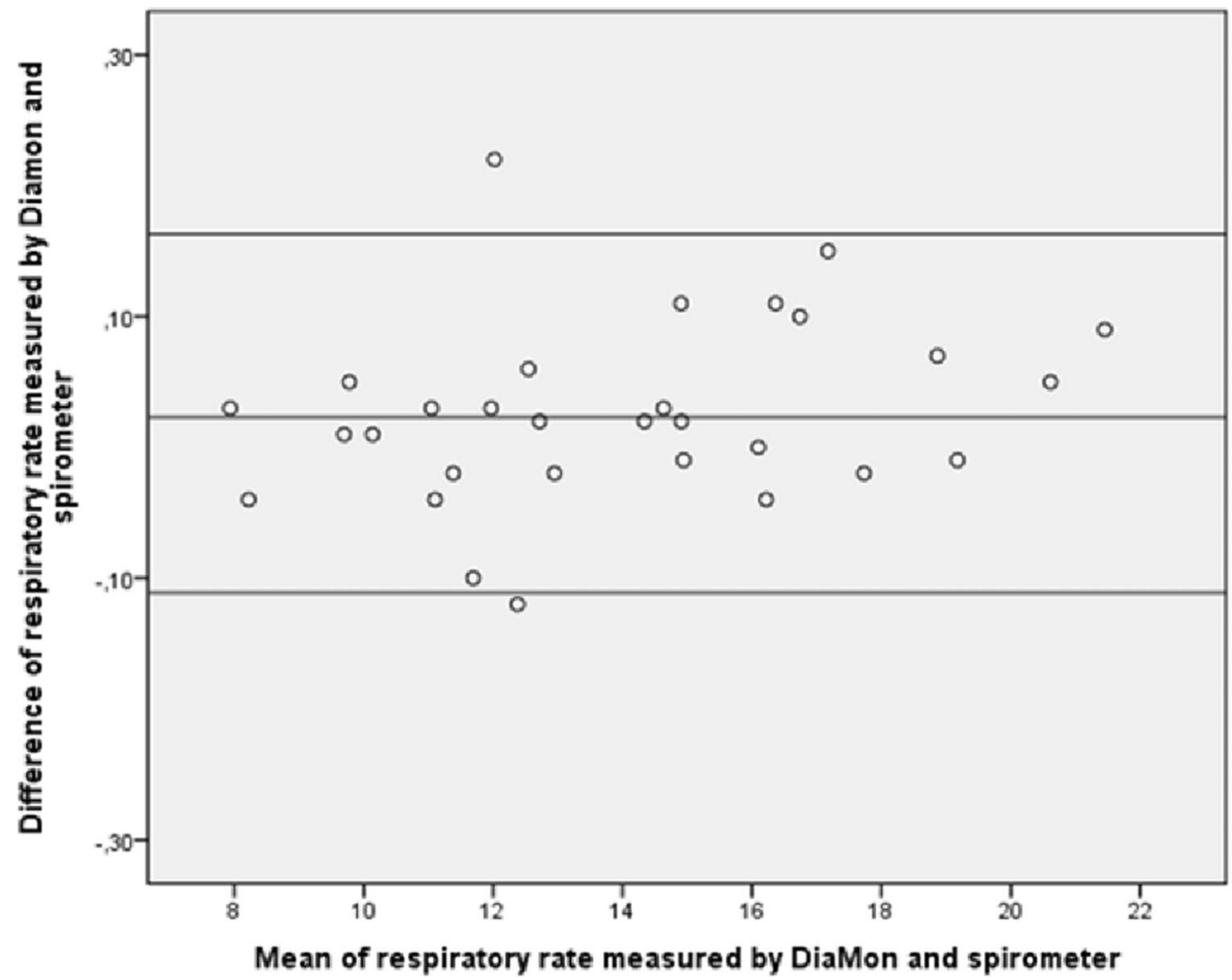

with an unavailable anterior axillary line, the paramidline or the midclavicular line can be used.

From a clinical point of view, the sitting posture might be used in a setting of weaning in the ICU or in a subacute setting in the pulmonary department. The probe was able to detect signals with different probe positions in $87-94 \%$ of the sitting subjects.

We observed that in the more medial positions (paramidline and midline), the probe detected the subjects' heartbeats as low-amplitude signals. In our subjects, the magnitude of the amplitudes were generally different than the ones detected from the movement of the diaphragm, but in patients with low-amplitude diaphragm movement, such as those on ventilators or with reduced diaphragmatic motility, this might be a problem. This was not observed in the anterior axillary-supine position.

An increasing respiratory frequency is a clinical sign of deterioration. Detecting this at an early stage could possibly allow for adjustments in the treatment, be it in the general ward or the intensive unit. The DiaMon device provides the clinician with a tool able to track the respiratory frequency continuously with excellent accuracy, possibly allowing for early escalation of therapy, and avoidance of more serious events. The device might prove a useful tool when estimating patients' breathing capacity when weaning from respirators, as an adjunct to a spontaneous breathing trial. It opens up to the possibility that one could leave the probe in place for a prolonged period of time, and thus follow the development over days, as well as intermittently placing it for re-measurement. It could also prove useful as a means of triggering mechanical ventilators, both invasive and non-invasive. One could imagine using it as a means of diagnostically measuring the respiratory effort in polysomnographies in sleep medicine, and possibly for measuring the strength of the diaphragm in patients with neuromuscular diseases and suspected diaphragmatic dysfunction from other causes. These possibilities require further investigation.

There are limitations to our study. The subjects were all healthy, and none were obese, although a few were overweight. This might differ from the population in an ICU, and might influence the capability of the probe to capture a usable signal. In addition, the probe did not remain attached for a prolonged period of time. The examination lasted between one and $2 \mathrm{~h}$ in total, with frequent changes in both probe positioning and subject posture, and it remains to be seen how the probe will behave when applied for several hours or days. It might also be a challenge when the skin is not dry, as can be the case in critical care patients. So far, this does not seem to be a problem, but it has to be explored further. Interindividual differences between personnel applying the probe also needs to be further evaluated, as does the amount of training and surveillance needed to obtain reliable measurements between operators. 


\section{Conclusion}

In conclusion, we have shown that the DiaMon device is able to detect signals derived from the movement of the liver in most subjects, and that the anterior axillary-supine position provides the best signals. As a backup in situations where this probe position is not available, the paramidline-supine position provides an alternative. The probe estimates the breathing frequency with excellent accuracy.

\section{Compliance with ethical standards}

Conflict of interest Two of the authors were employees at Respinor at the time of writing the article. Respinor contributed funds equivalent to $20 \%$ of the gross salary of the main author for the time used preparing the protocol and gathering the data. The authors have no other conflict of interests.

\section{References}

1. Walaszek M, Kosiarska A, Gniadek A, Kolpa M, Wolak Z, Dobros W, Siadek J (2016) The risk factors for hospital-acquired pneumonia in the Intensive Care Unit. Przegl Epidemiol 70(1):15-20

2. Ranjan N, Chaudhary U, Chaudhry D, Ranjan KP (2014) Ventilator-associated pneumonia in a tertiary care intensive care unit: analysis of incidence, risk factors and mortality. Indian J Crit Care Med 18(4):200-204. https://doi.org/10.4103/0972-5229.130570

3. Hortal J, Giannella M, Perez MJ, Barrio JM, Desco M, Bouza E, Munoz P (2009) Incidence and risk factors for ventilator-associated pneumonia after major heart surgery. Intensiv Care Med 35(9):1518-1525. https://doi.org/10.1007/s00134-009-1523-3

4. Halpern NA, Pastores SM, Greenstein RJ (2004) Critical care medicine in the United States 1985-2000: an analysis of bed numbers, use, and costs*. Crit Care Med 32(6):1254-1259. https://doi. org/10.1097/01.ccm.0000128577.31689.4c

5. McCool FD, Tzelepis GE (2012) Dysfunction of the diaphragm. N Engl J Med 366(10):932-942. https://doi.org/10.1056/NEJMr a1007236

6. Levine S, Nguyen T, Taylor N, Friscia ME, Budak MT, Rothenberg P, Zhu J, Sachdeva R, Sonnad S, Kaiser LR, Rubinstein NA, Powers SK, Shrager JB (2008) Rapid disuse atrophy of diaphragm fibers in mechanically ventilated humans. N Engl J Med 358(13):1327-1335. https://doi.org/10.1056/NEJMoa070447

7. Jung B, Nougaret S, Conseil M, Coisel Y, Futier E, Chanques G, Molinari N, Lacampagne A, Matecki S, Jaber S (2014) Sepsis is associated with a preferential diaphragmatic atrophy: a critically ill patient study using tridimensional computed tomography. Anesthesiology 120(5):1182-1191. https://doi.org/10.1097/ ALN.0000000000000201

8. Funk GC, Anders S, Breyer MK, Burghuber OC, Edelmann G, Heindl W, Hinterholzer G, Kohansal R, Schuster R, Schwarzmaier-D'Assie A, Valentin A, Hartl S (2010) Incidence and outcome of weaning from mechanical ventilation according to new categories. Eur Respir J 35(1):88-94. https://doi. org/10.1183/09031936.00056909

9. Esteban A, Alia I, Tobin MJ, Gil A, Gordo F, Vallverdu I, Blanch L, Bonet A, Vazquez A, de Pablo R, Torres A, de La Cal MA, Macias S (1999) Effect of spontaneous breathing trial duration on outcome of attempts to discontinue mechanical ventilation. Spanish Lung Failure Collaborative Group. Am J Respir Crit Care Med 159(2):512-518. https://doi.org/10.1164/ajrccm.159.2.98031 06

10. Esteban A, Alia I, Gordo F, Fernandez R, Solsona JF, Vallverdu I, Macias S, Allegue JM, Blanco J, Carriedo D, Leon M, de la Cal MA, Taboada F, Gonzalez de Velasco J, Palazon E, Carrizosa F, Tomas R, Suarez J, Goldwasser RS (1997) Extubation outcome after spontaneous breathing trials with T-tube or pressure support ventilation. The Spanish Lung Failure Collaborative Group. Am J Respir Crit Care Med 156(2 Pt 1):459-465. https://doi. org/10.1164/ajrccm.156.2.9610109

11. Jiang JR, Tsai TH, Jerng JS, Yu CJ, Wu HD, Yang PC (2004) Ultrasonographic evaluation of liver/spleen movements and extubation outcome. Chest 126(1):179-185. https://doi. org/10.1378/chest.126.1.179

12. Spadaro S, Grasso S, Mauri T, Dalla Corte F, Alvisi V, Ragazzi R, Cricca V, Biondi G, Di Mussi R, Marangoni E, Volta CA (2016) Can diaphragmatic ultrasonography performed during the T-tube trial predict weaning failure? The role of diaphragmatic rapid shallow breathing index. Crit Care. https://doi. org/10.1186/s13054-016-1479-y

13. Matamis D, Soilemezi E, Tsagourias M, Akoumianaki E, Dimassi S, Boroli F, Richard JC, Brochard L (2013) Sonographic evaluation of the diaphragm in critically ill patients. Technique and clinical applications. Intensiv Care Med 39(5):801-810. https://doi.org/10.1007/s00134-013-2823-1

14. Dube BP, Dres M, Mayaux J, Demiri S, Similowski T, Demoule A (2017) Ultrasound evaluation of diaphragm function in mechanically ventilated patients: comparison to phrenic stimulation and prognostic implications. Thorax. https://doi. org/10.1136/thoraxjnl-2016-209459

15. Ayoub J, Cohendy R, Dauzat M, Targhetta R, De la Coussaye JE, Bourgeois JM, Ramonatxo M, Prefaut C, Pourcelot L (1997) Non-invasive quantification of diaphragm kinetics using m-mode sonography. Can J Anaesth 44(7):739-744. https://doi. org/10.1007/BF03013389

16. Konno K, Mead J (1967) Measurement of the separate volume changes of rib cage and abdomen during breathing. J Appl Physiol 22(3):407-422. https://doi.org/10.1152/jappl.1967.22.3.407

17. Shahshahani A, Laverdiere C, Bhadra S, Zilic Z (2018) Ultrasound sensors for diaphragm motion tracking: an application in non-invasive respiratory monitoring. Sensors (Basel, Switzerland). https://doi.org/10.3390/s18082617

18. Fekr AR, Radecka K, Zilic Z (2015) Design and evaluation of an intelligent remote tidal volume variability monitoring system in e-health applications. IEEE J Biomed Health Inform 19(5):1532-1548. https://doi.org/10.1109/JBHI.2015.2445783

19. Nilsson L, Johansson A, Kalman S (2005) Respiration can be monitored by photoplethysmography with high sensitivity and specificity regardless of anaesthesia and ventilatory mode. Acta Anaesthesiol Scand 49(8):1157-1162. https://doi.org/10.111 1/j.1399-6576.2005.00721.x

20. Yang J, Cai J, Wang H, Chang Z, Czito BG, Bashir MR, Palta $M$, Yin FF (2014) Is diaphragm motion a good surrogate for liver tumor motion? Int J Radiat Oncol Biol Phys 90(4):952958. https://doi.org/10.1016/j.ijrobp.2014.07.028

21. Korin HW, Ehman RL, Riederer SJ, Felmlee JP, Grimm RC (1992) Respiratory kinematics of the upper abdominal organsa quantitative study. Magn Reson Med 23(1):172-178. https:// doi.org/10.1002/mrm.1910230118

22. Bellani G, Pesenti A (2014) Assessing effort and work of breathing. Curr Opin Crit Care 20(3):352-358. https://doi. org/10.1097/MCC.0000000000000089

23. Cohn D, Benditt JO, Eveloff S, McCool FD (1997) Diaphragm thickening during inspiration. J Appl Physiol 83(1):291-296 
24. Ferrari G, De Filippi G, Elia F, Panero F, Volpicelli G, Apra F (2014) Diaphragm ultrasound as a new index of discontinuation from mechanical ventilation. Crit Ultrasound J 6(1):8. https:// doi.org/10.1186/2036-7902-6-8

25. Gethin-Jones TL, Noble VE, Morse CR (2010) Quantification of diaphragm function using ultrasound: evaluation of a novel technique. Ultrasound Med Biol 36(11):1965-1969. https://doi. org/10.1016/j.ultrasmedbio.2010.08.003

26. Testa A, Soldati G, Giannuzzi R, Berardi S, Portale G, Gentiloni Silveri N (2011) Ultrasound M-mode assessment of diaphragmatic kinetics by anterior transverse scanning in healthy subjects. Ultrasound Med Biol 37(1):44-52. https:// doi.org/10.1016/j.ultrasmedbio.2010.10.004

27. Zanforlin A, Smargiassi A, Inchingolo R, Valente S, Ramazzina E (2015) Ultrasound in obstructive lung diseases: the effect of airway obstruction on diaphragm kinetics. A short pictorial essay. J Ultrasound 18(4):379-384. https://doi.org/10.1007/s4047 7-014-0122-5

28. Zanforlin A, Smargiassi A, Inchingolo R, di Marco Berardino A, Valente S, Ramazzina E (2014) Ultrasound analysis of diaphragm kinetics and the diagnosis of airway obstruction: the role of the M-mode index of obstruction. Ultrasound Med Biol 40(6):10651071. https://doi.org/10.1016/j.ultrasmedbio.2013.12.009

29. Cretikos MA, Bellomo R, Hillman K, Chen J, Finfer S, Flabouris A (2008) Respiratory rate: the neglected vital sign. Med J Aust 188(11):657-659

30. Vincent JL, Einav S, Pearse R, Jaber S, Kranke P, Overdyk FJ, Whitaker DK, Gordo F, Dahan A, Hoeft A (2018) Improving detection of patient deterioration in the general hospital ward environment. Eur J Anaesthesiol 35(5):325-333. https://doi. org/10.1097/EJA.0000000000000798
31. Fieselmann JF, Hendryx MS, Helms CM, Wakefield DS (1993) Respiratory rate predicts cardiopulmonary arrest for internal medicine inpatients. J Gen Intern Med 8(7):354-360

32. Mochizuki K, Shintani R, Mori K, Sato T, Sakaguchi O, Takeshige K, Nitta K, Imamura H (2017) Importance of respiratory rate for the prediction of clinical deterioration after emergency department discharge: a single-center, case-control study. Acute Med Surg 4(2):172-178. https://doi.org/10.1002/ams2.252

33. Kenzaka T, Okayama M, Kuroki S, Fukui M, Yahata S, Hayashi H, Kitao A, Sugiyama D, Kajii E, Hashimoto M (2012) Importance of vital signs to the early diagnosis and severity of sepsis: association between vital signs and sequential organ failure assessment score in patients with sepsis. Intern Med 51(8):871-876. https:// doi.org/10.2169/internalmedicine.51.6951

34. Van Leuvan CHM, Mitchell I (2008) Missed opportunities? an observational study of vital signs measurements. Crit Care Resusc 10:111-115

35. Philip KEJ, Pack E, Cambiano V, Rollmann H, Weil S, O’Beirne J (2014) The accuracy of respiratory rate assessment by doctors in a London teaching hospital: a cross-sectional study. J Clin Monit Comput 29(4):455-460. https://doi.org/10.1007/s1087 7-014-9621-3

Publisher's Note Springer Nature remains neutral with regard to jurisdictional claims in published maps and institutional affiliations. 